\title{
Gênero, sexualidade e políticas públicas de educação: um diálogo com a produção acadêmica
}

Resumo: Este artigo traz resultados de levantamentos da produção acadêmica sobre a introdução do gênero e da sexualidade nas políticas públicas de educação no Brasil entre 1990 e 2009. O conjunto de obras examinadas concentra 73 títulos. Elas acompanham o desenvolvimento das políticas públicas de educação, as quais vêm enfatizando o currículo, e indicam atualmente a construção de uma agenda de políticas voltadas para a diversidade sexual, com a criação de muitos projetos e programas. A maioria dessa produção, muito recente e centrada no Sul e no Sudeste, é composta por dissertaçóes, artigos de divulgação destas e ensaios, com um número reduzido de teses. Por meio da análise desse material identificaram-se dois movimentos analíticos: o uso do conceito de gênero, sob influência de Joan Scott, e, nas produçóes mais recentes, a crítica ao que Judith Butler denomina de "matriz heterossexual".

Palavras-chave: educação; gênero; políticas públicas; sexualidade; produção acadêmica.

Gender, sexuality and public educational policies: a dialogue with the academic production

Abstract: This article brings out the results of data from the academic production about the introduction of gender and sexuality in the public educational policies in Brazil between 1990 and 2009. The study involved 73 titles.Most of them, recent and produced mainly in the south and southeast regions of the country, consist of dissertations, articles related of them and essays, being just a few of them doctoral thesis. They follow the development of the public educational policies that have been focusing on the curriculum and indicate nowadays the construction of an agenda of sexual diversity policies through the creation of many projects and programs. When analyzing the above mentioned material, two analytical movements were identified: the use of the concept of gender, under the influence of Joan Scott and, in the most recent productions, the criticism to what Judith Butler calls the heterosexual matrix.

Key words: education; gender; public policies; sexuality; academic production.

Professora da Faculdade de Educação da Universidade de São Paulo, SP, Brasil. cpvianna@usp.br 
A análise a que este texto se refere tem como fonte duas investigaçôes ${ }^{1}$ : uma finalizada em 2009 e outra em andamento. O exame de tal temática partiu da constatação do avanço da produçáo acadêmica que relaciona gênero, sexualidade e educação formal, indicados pela base de dados Win-isis, com 1.213 títulos, entre 1990 e 2006 (Vianna; Carvalho; Schilling; Moreira, 2011).

Ao tomar por base os 1.213 títulos localizados pelo levantamento acima mencionado, foram encontrados 38 estudos voltados para a dimensão da incorporaçáo da sexualidade e do gênero nas políticas educacionais. Foi na investigação mais recente, já referida, que pude constatar um crescimento fortemente localizado entre os anos 2007 e 2009. Ou seja, exatamente nesses últimos anos da década, a defesa e a introdução do gênero e da sexualidade nas políticas públicas de educação no Brasil passaram a despertar significativo interesse na produção acadêmica.

Há, então, 73 produçóes acadêmicas dedicadas ao tema (artigos, dissertaçôes de mestrado ou teses de doutorado), das quais 66 foram produzidas a partir de 2000 e, destas, 36, entre 2007 e 2009. A maioria concentra-se nas regióes sudeste e sul e é composta por dissertaçóes de mestrado produzidas em universidades públicas. O número de teses de doutorado é bem menor. No caso dos artigos, muitos reproduzem temas já tratados, pelos mesmos autores e autoras, nas dissertaçóes ou teses examinadas; outros se constituem como ensaios.

A produção acadêmica sobre a temática de gênero e sexualidade nas políticas públicas educacionais ainda é tímida. Os trabalhos começaram a aparecer em 1995, com acréscimo gradual das produçóes acadêmicas até 2009. Houve aumento irrelevante entre os períodos de 1995/1997 (2 artigos e uma dissertação de mestrado) e 1998/2000 (2 artigos e 2 dissertaçóes de mestrado). As teses de doutorado só apareceram a partir de 2002. De 2001 a 2003, foi encontrado um incremento na produção, com 14 documentos ( 4 artigos, 7 dissertaçóes de mestrado e 3 teses de doutorado). Ênfase mais acentuada apareceu nos dois últimos triênios ${ }^{2}$. Entre 2004 e 2006, registrei 16 documentos ( 8 artigos, 7 dissertaçóes de mestrado e uma tese de doutorado) e, entre 2007 e 2010, 36 documentos (2 artigos, 27 dissertaçóes de mestrado e 7 teses de doutorado).

\footnotetext{
I Agradeço o apoio do CNPq/PQ, a participação dos bolsistas Liane Rizatto, Karina Valdestilhas e Marcelo Daniliauskas, Jaqueline Silva e Natália da Cruz, além do auxílio de Maria da Graça Vieira, diretora da Biblioteca Ana Maria Popovic, da Fundação Carlos Chagas, na busca e na atualização dos dados.

2 Para estabelecer a cronologia, utilizei como referência os períodos trienais de avaliação dos Programas de Pós-Graduação definidos pela Capes (1995/1997; 1998/2000; 2001/2003; 2004/2006/2007/2009). Neste último triênio foram incluídos um artigo e uma dissertação de mestrado. O primeiro, apesar de ser publicado em 2010 , apresenta resultados de experiência de formação continuada oferecida pelo Núcleo de Gênero e Diversidade Sexual (NGDS) no Paraná em 2009. A segunda se constitui no primeiro trabalho que tem por foco a análise do processo de implementação do Programa Brasil sem Homofobia.
}

Pro-Posiçôes, Campinas, v. 23, n. 2 (68), p. 127-143, maio/ago. 2012 
As regióes sudeste, com 28 produçóes (22 dissertaçóes de mestrado e 6 teses de doutorado), e sul, com 13 (11 dissertaçóes de mestrado e 2 teses de doutorado), destacam-se na orientação de dissertaçóes e teses em relação às demais: região nordeste, com 7 ( 5 dissertaçóes de mestrado e 2 teses de doutorado); regiáo norte, com 5 (todas elas dissertações de mestrado); e centro-oeste, com 2 (uma dissertação de mestrado e uma tese de doutorado $)^{3}$.

Com a leitura integral de 73 resumos e 52 trabalhos, até o momento, noto uma passagem do sexo ao gênero na produção acadêmica examinada, mostrando que a área da educação passa a trilhar as pistas oferecidas pelos estudos feministas, que procuravam minar o poder de um modelo explicativo, calcado na imutabilidade das diferenças entre homens e mulheres; e recorre, em seguida, ao gênero, para referir-se à construção social das diferenças entre os sexos ao longo da história.

Outra evidência é a forte influência da produção da historiadora americana Joan Scott - inicialmente difundida no Brasil por Guacira Lopes Louro (1999, 2003, 2006) -, que deu maior amplitude ao conceito de gênero enquanto uma categoria analítica capaz de produzir conhecimento histórico. Com ênfase na perspectiva pós-estruturalista, centra o olhar no controle dos corpos enquanto um processo social e culturalmente determinado, permeado por formas sutis, muitas vezes não percebidas na produção das políticas e nas relaçôes estabelecidas no cotidiano escolar.

Foi também possível identificar um segundo movimento analítico no exame das produçôes mais recentes: a reflexão crítica, já no campo da diversidade sexual, do que Judith Butler $(1990,2009)$ denomina de "matriz heterossexual", ou seja, da imposição da heterossexualidade como padrão.

É evidente que nem o crescimento dessa produção nem os temas por ela priorizados se dão ao acaso. O contexto de formulação das políticas de educação e a produção acadêmica influenciam-se mutuamente na construção do que pode

3 Essa produção está localizada nas seguintes universidades: Universidade Federal do Rio Grande do Sul (06); PUC-SP (04); Unicamp (03); Universidade de São Paulo (03); Universidade Federal de Santa Catarina (03); Universidade Federal de Pernambuco (03); Universidade Federal Fluminense (02); Universidade do Estado do Rio de Janeiro (02); Universidade Federal do Amazonas (02); Universidade Tuiuti do Paraná (02); Universidade Federal do Paraná (02); Universidade Regional de Blumenau (O I); Unesp-Bauru (O I); Unesp-Marília (O I); Centro Universitário Moura Lacerda (OI); Universidade do Estado de Santa Catarina (OI); Universidade Federal da Bahia (OI); Universidade Federal do Ceará (OI); Universidade Federal de Rondônia (OI); Universidade Federal de Alagoas (OI); Universidade Federal do Pará (OI); Universidade Federal do Espírito Santo (O I); Universidade de Sorocaba (O I); Universidade Gama Filho (OI); Centro de Pesquisa Aggeu Magalhães/Fiocruz (O I); Universidade Federal de Uberlândia (O I); Universidade Católica de Petrópolis (O I ); Universidade Nove de Julho (0 I); Universidade Federal de Goiás (0 I); Centro de Pesquisas René Rachou/Fiocruz (OI); Universidade de Brasília (OI); Universidade Federal de Minas Gerais (0I); Universidade Federal de Juiz de Fora (0 I); Centro Federal de Educação Tecnológica de Minas Gerais (OI). 
caracterizar-se, quem sabe em futuro próximo, como um campo específico da produção acadêmica educacional.

\section{Sobre o contexto de elaboração das políticas e a reflexão acadêmica sobre o tema}

O exame das políticas públicas de educação, a partir da perspectiva das relaçóes sociais de gênero, e o contexto no qual elas são produzidas evidenciam um tenso processo de negociação, que determina a supressão e/ou a concretização de reformas, planos, projetos, programas e açôes implementados - separada ou articuladamente - pelo Estado e pelos movimentos sociais que pressionam por novas políticas públicas; pela ocupação de espaços na administração pública; e pelo reconhecimento de novas formas de desigualdade. Tanto o Estado quanto os movimentos, nas suas respectivas pluralidades, articulam-se e/ou disputam acirradamente interesses sociais que se fazem presentes nesse processo. Nessa arena de relaçóes necessariamente conflituosas e, por vezes, contraditórias, a formulação dessas políticas, bem como a produção de conhecimento sobre elas, remete à discussão de complexidades.

Os grupos em negociação com o Estado são influenciados por vertentes teóricas e açóes coletivas circunscritas, no caso do tema em foco, ao Movimento de Mulheres e ao Movimento Lésbicas, Gays, Bissexuais, Transexuais e Transgêneros $(\text { LGBTT })^{4}$. Este último assume papel protagonista na proposição de vários projetos e programas federais e estaduais ligados à inclusão da diversidade sexual no contexto escolar. Também exercem grande influência setores representativos de forças internacionais, com participação decisiva na vida nacional e na confecção de linhas de ação para as políticas públicas de educação.

Mais uma significativa presença nesse contexto foi a criação, na Associação Nacional de Pesquisa e Pós-Graduação em Educação (ANPEd), do Grupo de Trabalho "Gênero, Sexualidade e Educação" (GT 23) contribuição de pesquisadoras(es), docentes e estudantes em torno de questóes teóricas e práticas sob essa perspectiva de análise.

A discussão sobre a inclusão da sexualidade no currículo escolar é antiga, mas o mesmo não se pode dizer da proposição desta temática enquanto norteadora de políticas públicas federais na área da educação, menos ainda ao relacionar o tema da sexualidade ao reconhecimento da diversidade sexual. A retomada efetiva dessa questáo na área educacional deu-se a partir de 1995, com a pressáo de movimentos de mulheres e com as sucessivas respostas do governo de Fernando

4 O movimento homossexual brasileiro sofreu várias alterações; uma das denominações mais usadas atualmente pelo movimento é LGBTT (Lésbicas, Gays, Bissexuais, Transexuais e Transgêneros).

5 Após finalizar minha gestão como coordenadora no GT 03 "Movimentos Sociais e Educação" e voltar de minha estadia na Universidade Autônoma de Madri, passei também a integrar o GT 23.

Pro-Posições, Campinas, v. 23, n. 2 (68), p. 127-143, maio/ago. 2012 
Henrique Cardoso aos compromissos internacionais relativos a uma agenda de gênero e sexualidade.

Foi nesse contexto de forte influência das agências multilaterais, como o Banco Mundial, a Cepal e a Unesco, que se instaurou, sob coordenação do então Ministério da Educação e da Cultura (MEC), o processo de elaboração do Referencial Curricular Nacional para a Educação Infantil e dos Parâmetros Curriculares Nacionais (PCN) para o Ensino Fundamental como instrumentos de referência para a construção do currículo, a partir de uma perspectiva de gênero/sexualidade nas políticas públicas de educação escolar no Brasil, em substituição ao antigo currículo mínimo comum. A "relação entre educação, políticas públicas, Estado e desigualdades vai deixando lugar a políticas de inclusão, escola inclusiva, projetos inclusivos, currículos inclusivos" (Arroyo, 2010, p. 1391). Mas, se existe consenso na defesa de políticas inclusivas, o mesmo não se instaura "quando se trata de discutir o que deve ser feito, como deve ser feito, quando deve ser feito, quem está habilitado a fazer" (Seffner, 2009, p. 127).

Nesse processo, a própria Constituição Federal de 1988 já afirmava a necessidade e a obrigação de o Estado elaborar parâmetros para orientar as açóes educativas. Responde a essas orientaçóes uma série de documentos, entre eles os Parâmetros Curriculares Nacionais (PCN).

Lançados oficialmente em 1997, os PCN foram distribuídos por todo o território nacional, no início de 1998, pela Secretaria de Educação Fundamental do MEC e receberam, por parte dos educadores(as) em geral, alguns elogios e inúmeras críticas.

No âmbito da produção acadêmica sobre a introdução do gênero e da sexualidade nas políticas educacionais, há um grupo expressivo de dissertaçóes de mestrado voltadas especificamente para o exame dos PCN, que destaca seu ineditismo, considerado como um avanço no que diz respeito à "oficialização" do tema da sexualidade e do gênero no currículo e nas escolas (Altmann, 2001; Andrade, 2004; Assunção; Teixeira, 2000; Costa, 2001; Fava, 2004; Freitag, 2004; Lira, 2009; Marchi, 2000; Parré, 2001; Ribeiro, 2009; Silva, 2009; Vianna; Unbehaum, 2004, 2006).

Como ponto positivo também foi apontada a exigência da inclusão da sexualidade como tema transversal nas demais áreas de conhecimento que compóem o currículo. No entanto, muitas críticas foram observadas nesse processo. Entre especialistas e pesquisadores(as) da área educacional, lastimava-se, sobretudo, o caráter centralizador e prescritivo dos Parâmetros, sob forte influência dos organismos internacionais, com um currículo oculto altamente hierarquizado e sem açôes que pudessem minimizar a formação docente deficitária e a falta de condiçóes estruturais para que educadoras e educadores pudessem lidar com essa abordagem nas escolas. Segundo Teresa Cristina Bruno Andrade (2004), os temas transversais possuem uma metodologia fragmentada. Para ela, o conceito de transversalidade, 
com base teórica inconsistente, também não é capaz de questionar, de fato, a própria realidade macroestrutural que deveria dar alicerce às discussóes e às resoluçóes de problemas sociais.

O exame da aplicação das diretrizes curriculares sobre Orientação Sexual contidas nos PCN, a partir de observaçóes do cotidiano escolar e/ou de entrevistas e questionários aplicados aos docentes de uma determinada escola, também destaca as dificuldades de introduçáo do tema da sexualidade na escola, diante da falta de formação docente inicial e continuada; da precariedade de cursos descentralizados por parte de profissionais que já passaram por tal formação (multiplicadores); e da dificuldade pessoal em abordar o tema no cotidiano escolar (Assunção; Teixeira, 2000; Fava, 2004; Lira, 2009; Marchi, 2000; Ribeiro, 2009; Silva, 2009).

Além desses aspectos, os trabalhos realçam a subordinação das temáticas de gênero e sexualidade ao trinômio corpo/saúde/doença na Orientação Sexual, entendida como atividade meramente informadora e reguladora. Helena Altmann (2001) e Sandra Helena Gramuglia Parré (2001), por exemplo, reprovam a concepção de orientação sexual vinculada à visão de sexualidade que perpassa o documento e entendida como de caráter meramente informativo. Para Altman (2001, p. 580), a sexualidade é concebida nos parâmetros como um dado da natureza, como "algo inerente, necessário e fonte de prazer na vida", como "necessidade básica" ou "impulsos de desejo vividos no corpo", algo sobre o que os sujeitos, principalmente os jovens, precisariam ser informados. Ressalto, então, a vinculação entre sexualidade, tabus e preconceitos, sem que a Orientação Sexual proporcione, entre as pessoas que frequentam as instituiçóes escolares, discussóes valiosas sobre as próprias concepçóes relacionadas às atitudes de cada um na relação com o outro.

A essa crítica alinham-se as reflexôes sobre a polarização entre Orientação Sexual e as diferentes vertentes ligadas à Educação Sexual (Furlani, 2009). Porém, mesmo sem a clareza de qual termo ou conceito seria mais apropriado, prevalece a tônica ressaltada por Cláudia Ribeiro (2010, p. 150): "a Educação Sexual, ao invés de questionar valores, crenças e costumes, tem servido para adaptaçóes e readaptaçóes do que foge à normalidade".

É também objeto de condenação a pouca relevância da temática da diversidade sexual no contexto de elaboração dos PCN. Ela aparece apenas na introdução ao documento, na introdução aos temas transversais, e é citada somente uma vez no volume de Orientação Sexual dos PCN do primeiro ciclo, apenas para enfatizar que esse assunto deverá ser tratado da $5^{\mathrm{a}}$ série em diante (Daniliauskas, 2011). Já nos PCN dedicados ao segundo ciclo, sua menção se dá em um contexto que chama a atenção para as dificuldades de se tratar de tema tão complexo e controverso.

Assim, é possível afirmar, até este momento, a ênfase na redução da sexualidade à heterossexualidade e destacar a restrita menção da homossexualidade nos $\mathrm{PCN}$ e 
o silenciamento da discriminação sofrida pela população LGBTT. O que prevalece é a reiteração compulsória da heterossexualidade (Louro, 1999, 2009) e, fora os esforços de pioneiras(os) na área, são os trabalhos mais recentes os que vão problematizar essa questão, com destaque para a crítica ao processo de invisibilização da população LGBTT no cotidiano e na organização escolar.

Saindo do âmbito específico dos PCN, foi possível encontrar trabalhos recentes, já fortemente influenciados por Judith Butler e Michel Foucault, dedicados à reflexão sobre a presença do discurso sobre a sexualidade nas escolas. Sirlene Mota Pereira da Silva (2009) faz um estudo sobre a sexualidade da "mulher professora" e sua influência na prática educativa, ao analisar as representaçóes de professoras sobre a sexualidade e sobre a educação sexual, destacando como os mecanismos de controle social e os discursos de verdade influenciam o trabalho docente. Dulcilene Pereira Jardim (2009) e Elaine Beatriz Ferreira Dulac (2009) analisam os discursos sobre sexualidade que preponderam nas falas de professoras de diversas disciplinas da educação básica. Dulac destaca ainda alguns enunciados que compóem os campos discursivos da educação e da sexualidade, apontados nas entrevistas: a homossexualidade é um tema marginal na escola; é preciso educar para a diversidade e para a aceitaçáo da diversidade de gênero e sexual; nem todos os professores(as) podem falar de sexualidade na escola. Na mesma direção, Lindamara da Silva França (2008) e Santina Célia Bordini (2009) problematizam a concepção de sexualidade apresentada por professores(as) que atuam em escolas do Ensino Fundamental da rede pública de Curitiba. Por meio de entrevistas e observaçôes em distintas escolas e disciplinas, ambas as autoras ressaltam que a maioria docente ainda mantém uma visão restrita, coerente com a concepção médico-higienista.

Voltado para a identificação não só dos discursos, mas dos principais desafios, convergências e divergências enfrentados por docentes no trabalho com a educação sexual no âmbito escolar, um grande grupo de trabalhos nos remete às questôes que essa inserção necessariamente envolve (Lira, 2009; Marsiglia, 2009; Oliveira, 2009; Reis, 2009; Tuckmantel, 2009). As expectativas e os interesses de professores(as) e alunos(as) em relação ao debate sobre sexualidade no contexto escolar são múltiplos e, por vezes, contraditórios. Prevalecem as dificuldades em romper com os padróes tradicionais a respeito das identidades de gênero, mas também ganham espaço tentativas de ressignificação das concepçóes docentes para além da heteronormatividade no trabalho pedagógico.

Além disso, cabe destacar uma importante dimensão conceitual em todos esses trabalhos mais recentes: a imbricação entre gênero e sexualidade, considerados conceitos distintos, mas não excludentes. Alguns desses estudos já ampliam a análise do processo de democratização da educação e suas demandas para a população LGBTT, destacando seu caráter heteronormativo, aspecto a ser explorado no tópico seguinte. 
A diversidade sexual e a formulação de políticas públicas de educação

Ao tratar da introdução do gênero nas políticas públicas de educação, com especial visibilidade para as demandas em torno da diversidade sexual, é preciso lembrar a importância da saúde pública. Foi nesse setor que o debate se fez visível e viável, para depois ser, entáo, inserido nas demandas realizadas por setores da sociedade civil à área da educação.

Nos anos 1990 e no início do século XXI, ocorreram mudanças significativas no panorama dos temas ligados à homossexualidade, ocasionando transformaçóes no quadro de visibilidade da temática, com a multiplicação de iniciativas no campo legislativo, da justiça e de extensáo de direitos (Silva, 2010). Entretanto, foi no governo Lula que a diversidade passou a ser reconhecida, a partir da negociaçáo e da representatividade no governo de diversos atores políticos, como integrantes não só de programas e projetos, mas da própria organização administrativa, ocasionando uma modificação no modelo institucional de algumas secretarias, inexistente nos governos anteriores.

Foram criadas várias secretarias especiais, entre elas: a Secretaria Especial de Direitos Humanos (SEDH), a Secretaria Especial de Política para Mulheres (SPM), a Secretaria Especial da Promoção da Igualdade Racial (SEPPIR) e a Secretaria Nacional da Juventude (SNJ). A participação desses atores no próprio governo somou-se às pressóes advindas das Conferências Nacionais, locais de produção e negociação de agendas políticas que, muitas vezes, resultavam na criação de novas responsabilidades governamentais e de tentativas de "introdução de diretrizes respeitosas à diversidade sexual", referência no campo do currículo; da formação docente; e das relaçóes estabelecidas no ambiente escolar, com o intuito de propiciar, como afirma Roger Raup Rios (2009, p.78), a "superação de preconceitos e discriminaçôes já consolidados”.

Sob as injunçôes desses processos materializa-se a ênfase na inclusão social e também se organizam novas institucionalidades. No âmbito específico do Ministério da Educação, instituíram-se a Secretaria de Inclusão Educacional (Secrie) e a Secretaria Extraordinária de Erradicação do Analfabetismo (Seea). E, com a fusão destas secretarias, em abril de 2004, origina-se a Secretaria de Educação Continuada, Alfabetização e Diversidade (Secad). Iniciou-se, então, a tentativa de articular as açôes de inclusão social com a valorização da diversidade e com o destaque às demandas até então invisibilizadas e não atendidas efetivamente pelos sistemas públicos de educação.

A partir da criação da Secad, canalizaram-se para a agenda governamental do MEC temas e sujeitos que dela estavam excluídos. Com a presença desses setores nos espaços da administração pública, assistimos à conversão de antigas denúncias em propostas de políticas públicas federais. 
É essa secretaria que se incumbe de traduzir as propostas de desenvolvimento de açôes no âmbito da educação gestadas em outros programas e planos mais gerais. Esse foi o caso, por exemplo, da organização do primeiro Plano Nacional de Políticas para as Mulheres (PNPM), em 2004, e de sua segunda versáo, em 2008, ambos antecedidos pelas Conferências de Políticas para as Mulheres (2004 e 2007) e do Programa Brasil Sem Homofobia (BSH), precedido pelo Plano Plurianual (PPA 2004-2007).

O primeiro PNPM (2004) tinha entre seus objetivos a educação inclusiva e não sexista, visando a promover o acesso à educação básica de mulheres jovens e adultas. Já o Plano Plurianual (PPA 2004-2007), lançado em 2004, definia o Plano de Combate à Discriminação contra Homossexuais. Com vistas a efetivar esse compromisso, a Secretaria Especial de Direitos Humanos (SEDH) acolheu demandas do movimento LGBTT apresentadas em encontros nacionais e lançou o Programa Brasil Sem Homofobia (BSH), de combate à violência física, verbal e simbólica, sofrida por pessoas LGBTT' L $^{\text {O }}$ referido Programa traz um capítulo dedicado à educaçáo, com o objetivo de promover valores de respeito à paz e à não discriminação por orientação sexual. A tarefa de implementação dessas políticas de inclusão é coordenada pela Secad, na perspectiva de educação para a diversidade. Para tal intento, a Secretaria considera fundamental incluir a interlocução da diversidade sexual com a discussão da temática de gênero.

Enfim, ainda que sob forte tensão, são assumidas, no plano federal, diferentes demandas para a constituição de políticas públicas voltadas à diversidade, apresentadas principalmente pelos movimentos sociais. O fato de as Organizações Não Governamentais receberem mais incentivos para a produção de pesquisas voltadas para a diversidade sexual e para as desigualdades de gênero também foi um marco no primeiro mandato do presidente Lula.

Amplia-se a adoção de mecanismos de participação de movimentos sociais organizados, por meio de fóruns, seminários, conferências e outros espaços organizados para mobilizar atores e temas considerados relevantes para o desenvolvimento de políticas para a inclusão e a diversidade. Reúnem-se, assim, gestores dos sistemas de ensino, autoridades locais, representantes de movimentos e organizaçóes sociais e dos segmentos diretamente interessados no avanço dessa agenda.

Na mesma direção, Nina Madsen (2008) ressalta o apoio do MEC às inúmeras iniciativas da Secretaria Especial de Políticas para as Mulheres (SPM) na área da

6 Nesse processo destaco a complementaridade entre Estado e movimento social na formulação das políticas voltadas ao segmento LGBTT. Elas não só nascem no próprio movimento e são incorporadas pelo governo, mas também expressam uma espécie de parceria. No caso do BSH, o documento final é assinado por um representante do governo (SEDH) e outro da Associação Brasileira de Gays, Lésbicas, Bissexuais, Travestis e Transexuais (ABGLT), com a participação de uma série de outras associações, ministérios, secretarias e organismos de pesquisa. 
educação, destacando um importante movimento na formulação das políticas a partir de 2003. O mesmo aconteceu com as açóes educacionais propostas pelo Programa Brasil Sem Homofobia. Parte das principais políticas públicas que visam a superar a desigualdade relacionada às pessoas LGBTT, por meio da educação no âmbito do referido Programa, é expressáo das respostas dadas pelo Estado a pressôes, sugestôes, participaçôes e interferências do movimento LGBTT (Rossi, 2010).

Nesse processo, posso assegurar que a diversidade está presente em programas e projetos do MEC. Entre eles, destacam-se os relacionados às temáticas de gênero, sexualidade e diversidade sexual na formação continuada docente.

Alguns trabalhos acadêmicos mais recentes já refletem sobre as características e os efeitos das atuais políticas públicas acerca da diversidade sexual propostas para a educação em diferentes instituiçóes de ensino, considerando alguns dos programas do governo, como: Brasil Sem Homofobia (Daniliauskas, 2011; Dulac, 2009; Quartieiro, 2009; Rossi, 2010); Gênero e Diversidade na Escola (Caldas, 2007; Ferrari, 2004; Grösz, 2008; Koerich, 2007; Mostafa, 2009); Capacitação de Multiplicadores(as) em Gênero e Políticas Públicas (Esperança, 2009; Santos, 2008; Santos, 2009).

Essas reflexôes também se desdobram nos debates e nas deliberaçóes da VI Conferência Nacional de Educação (Conae/2010), inserindo questôes da inclusão e da diversidade na pauta das políticas educacionais do Brasil. Na proposição das metas para elaboração do Plano Nacional de Educação (PNE), é relevante o eixo que teve como título Justiça Social, Educação e Trabalho: Inclusão, Diversidade e Igualdade. O projeto de lei do Plano Nacional de Educação para o decênio 20112020, encaminhado ao Congresso Nacional em dezembro de 2010 e ainda em discussão, propóe uma série de diretrizes para planejar e organizar a educação. Três conceitos fundamentam a sua décima diretriz: a equidade, o respeito à diversidade e a gestão democrática da educação. Ainda no referido documento, consta a meta que propóe universalizar, até 2016, o atendimento escolar para toda a população de 15 a 17 anos e elevar, até 2020, a taxa líquida de matrículas no Ensino Médio para $85 \%$, nesta faixa etária. Uma das estratégias para tal finalidade é prevenir a evasão motivada por preconceito e discriminação à orientação sexual ou à identidade de gênero.

O exame da produção acadêmica sobre o tema específico deste artigo permite uma análise comparativa de dois governos, com dois períodos cada um: 1994/1998-1999/2002 e 2003/2005-2006/2010. E, a partir da reflexão histórica aqui construída, posso afirmar duas das principais características contraditórias dessas políticas. Sofrem a pressão de agências multilaterais em favor de uma concepção de educação ora compensatória, ora parcialmente inclusiva e necessariamente precária, tanto no acesso quanto em sua qualidade. Ao mesmo tempo, 
com maior ênfase no governo Lula, assistiu-se à porosidade do governo federal às demandas de movimentos sociais organizados e ao crescimento destes enquanto sujeitos coletivos formuladores de políticas públicas.

Assim, arrisco dizer que a presença de novos sujeitos coletivos - propositores e formuladores de políticas públicas na educação - provocou tensóes e confrontos entre projetos políticos divergentes; alterou o que era rotulado como conhecimento, valores e condutas aceitáveis; redefiniu a própria dinâmica de confecção dessas políticas e, consequentemente, o papel do Estado, com efeitos importantes para a realidade educacional brasileira.

Aos menos no campo específico da introdução das questôes de sexualidade, diversidade sexual e gênero aqui observado, os movimentos traduziram algumas das questốes teóricas para o plano da prática social. Também merece realce o reconhecimento de direitos relativos às sexualidades menosprezadas e que têm impacto nas relaçóes escolares, como, por exemplo, a construção do currículo pautado pelo respeito aos direitos humanos relacionados à diversidade sexual (Rios, 2009; Silva, 2010).

Nesse processo evidencia-se a inclusão da sexualidade e do gênero no currículo e na formação continuada docente, já com indícios de ressignificação das concepçóes sobre sexualidade no trabalho pedagógico (Andrade, 2008; Lira, 2009; Reis, 2009).

Todavia, esse contexto está necessariamente permeado por retrocessos e resistências que impóem novos desafios teóricos e práticos para a própria elaboração das políticas públicas e para a reflexão acadêmica sobre esse processo. Esse é o caso, por exemplo, da pouca importância dada ainda hoje para a relaçáo entre nacionalidade e sexualidade e para o caráter sexuado do Estado e de suas políticas nacionais e locais, que interpretam e regulam várias das concepçôes de família, reprodução, educação, estilo de vida, muitas delas entrelaçadas com a construção das relaçóes de gênero. Dessa analogia depende a regulamentação do aborto e da reproduçáo, o estabelecimento de uma idade consentida para relaçôes sexuais e para o casamento, bem como a criminalização das práticas que não se adequem a essas regras (Epstein; Johnson, 2000).

O reconhecimento de consensos construídos e negociados em torno da relevância das políticas da diversidade permite considerar que a disputa em torno das concepçóes e da articulação dos espaços de diálogo ainda se constitui em amplo desafio para consolidar, de fato, essa trajetória institucional em política pública de Estado. Na mesma linha, novos conceitos - como gênero, sexualidade, homofobia, heteronormatividade - não são assumidos como definidores das políticas públicas para a educação, sejam elas federais, estaduais ou municipais.

Um dos percalços a ser enfrentado é a própria fragmentação do uso do conceito de diversidade, o que "expressa, no limite, as disputas internas e externas ao governo pela definição de projetos educacionais, propondo modos distintos 
de responder às demandas de movimentos sociais no reconhecimento de suas múltiplas diversidades" (Moehlecke, 2009, p. 484). Somam-se a esse obstáculo a própria resistência interna ao MEC (Junqueira, 2009; Madsen, 2008) e a enorme dificuldade em romper com os padróes tradicionais a respeito das identidades de gênero. Os mecanismos de controle social ainda têm peso na construção de novos sentidos sobre a sexualidade e influenciam as políticas e as práticas educativas. A proibição de falar sobre sexualidade é uma constante. Mesmo quando aberta a possibilidade de diálogo sobre o tema, este fica restrito à concepção médicohigienista da sexualidade e aos professores de ciências e biologia (Bordini, 2009; Dulac, 2009; França, 2008), registrando-se um verdadeiro pânico moral, ao mencionar-se a possibilidade de seu tratamento para além da visão heteronormativa (Borges; Meyer, 2008).

Nessa mesma linha, as garotas homossexuais fazem parte de um campo de disputa que permanece silenciado. Não excluído, pois "o silêncio e a invisibilidade forçada não devem ser confundidos com sinal de ausência” (Cavaleiro, 2010, p. 177-178), mas ainda inferiorizado e não reconhecido. Além disso, a própria inserção das demandas advindas dos movimentos de mulheres e da população LGBTT não garante a superação das relaçóes de poder que definem parâmetros tradicionais que sustentam as relaçóes de gênero em nossa sociedade.

Além dos enfrentamentos já elencados, a tentativa até aqui desenvolvida de articulação dos resultados das pesquisas aponta-nos também desafios acadêmicos para a produçáo de novos conhecimentos sobre essa realidade em construção. Menciono apenas três possíveis urgências.

Uma delas diz respeito à retomada da reflexão sobre os conceitos de desigualdade e diversidade. A meu ver, não se trata de tarefa individual. Será necessária, novamente, a articulação de muitos debates para sair desta noçáo enquanto mera diversificação e situar a diversidade no contexto de produçấo de desigualdades sociais e de enfrentamento de necessidades radicais.

Outra pauta urgente para investigaçôes futuras se dirige à constituição da formação docente voltada para o trabalho com a diversidade e para o combate à sua transformação em desigualdade. Até o momento, muitos programas de formação continuada são formulados e postos em ação, mas ainda não temos a exata dimensão de como estruturar essa agenda na formação inicial docente e de introduzir essa temática para além da mera informação. A discussão da sexualidade e do gênero está impregnada de valores e significados constitutivos da socialização de homens e mulheres. A compreensão do sexo que nos constitui, reduzindo-o às características físicas e naturais coladas à concepção biológica, ao cuidado do corpo e à prevenção de doenças ainda é vista como universal e a-histórica. Esses valores configuram a própria identidade docente, bem como as identidades de gênero chanceladas nas normas e relaçóes escolares. Não será, portanto, por meio de uma formação breve 
e/ou a distância que conseguiremos garantir a desconstrução dessas desigualdades de gênero. Aliás, não será sequer apenas na formação docente que essa tarefa poderá ser plenamente enfrentada. A formação docente é uma das múltiplas searas nas quais poderemos adquirir mecanismos de superação de algumas ideias preconcebidas e construir novos conhecimentos e práticas. Todavia, uma revisão curricular deve envolver todos, sobretudo as universidades públicas e privadas; e não deve, no entanto, incluir apenas a perspectiva de gênero, mas também a de raça/etnia, orientação sexual, classe, geração e todas as dimensôes que perpassam a construção das desigualdades e atentam para as possibilidades de ruptura e de construção de novas definiçôes do que é socialmente concebido.

Uma terceira e última urgência dirige-se ao caráter federativo do Estado brasileiro, em particular à leitura que os governos estaduais e municipais fazem das políticas federais e à forma como essa discussão é apropriada por docentes e demais funcionários das escolas públicas, para não entrar no mérito específico das escolas privadas. Essas propostas ainda são muito centralizadas na sua elaboração e necessitariam envolver todos os responsáveis pela educação. Essa é uma tarefa difícil e requer luta em todas as esferas, dentro e fora da escola: na conscientização e na formação do corpo docente; na discussão de propostas e atividades realizadas na escola; na análise crítica dos livros didáticos; na denúncia das revelaçóes ditas científicas que perpetuam preconceitos; e, sobretudo, nas inúmeras reivindicações por direitos à diferença. Assim, as proposiçôes políticas, articuladas à produção de conhecimento acadêmico sobre elas, poderão, espero, produzir outras e múltiplas alternativas aos desafios e às urgências aqui apontados.

\section{Referências bibliográficas}

ALTMANN, H. Orientação sexual nos Parâmetros Curriculares Nacionais. Estudos Feministas - CFH/CCE/UFSC, Florianópolis, v. 9, n. 2, p. 575-585, 2001.

ANDRADE, T. Dos temas transversais à apropriaçãolvivência de valores: uma proposta de qualidade sócio-educacional. Dissertação (Mestrado) - Unesp, Marília, 2004.

ANDRADE, V. Orientação sexual na escola: o que pensam alunas/adolescentes do ensino fundamental. Dissertação (Mestrado) - UCP, Petrópolis, 2008.

ARROYO, M. Políticas educacionais e desigualdades: à procura de novos significados. Educação e Sociedade, Campinas, v. 31, n. 113, p. 1381-1416, 2010.

ASSUNÇÃO, M.; TEIXEIRA, A. Relações de gênero: em sintonia com os PCNs. Amae Educando, Belo Horizonte, v. 33, n. 295, p.4 1-45, out. 2000.

BORDINI, S. Discursos sobre sexualidade nas escolas municipais de Curitiba. Dissertação (Mestrado) - UFP, Curitiba, 2009. 
BORGES, Z.; MEYER, D. Limites e possibilidades de uma ação educativa na redução da vulnerabilidade à violência e à homofobia. Ensaio. Avaliação e Políticas Públicas em Educação, v. 16, n. 58, p. 59-76, jan./mar. 2008.

BUTLER, J. Gender Trouble: Feminism and the subversion of identity. New York; London: Routledge; Champman \& Hall, 1990.

BUTLER, J. Performatividad, precariedad y políticas sexuales. Revista de Antropología Iberoamericana - Antropólogos Iberoamericanos en Red, Madrid, v. 4, n. 3, p. 321-36, set./dez. 2009.

CALDAS, C. A. A. A escola faz diferença? Um estudo da produção discursiva das homossexualidades por professores de ensino médio. Dissertaçáo (Mestrado) - UFP, Belém, 2007.

CAVALEIRO, M. C. Feminilidades homossexuais no ambiente escolar: ocultamentos e discriminações vividas por garotas. Tese (Doutorado) - Feusp, São Paulo, 2009.

COSTA, M. As complexas conexôes entre gênero, profissionalismo e formação docente. Movimento - Faculdade de Educaçáo da Universidade Federal Fluminense, Rio de Janeiro, n. 3, p. 11-28, maio 2001.

COSTA, R. Sexualidade como tema transversal: a estruturação da educação sexual nos Parâmetros Curriculares Nacionais. Dissertação (Mestrado) - UFSC, Florianópolis, 2001.

DANILIAUSKAS, M. Relaçôes de gênero, diversidade sexual e politicas públicas de educação: uma análise do Programa Brasil Sem Homofobia. Dissertação (Mestrado) - Feusp, São Paulo, 2011.

DULAC, E. Sexualidades e escola: considerações e questōes levantadas pelos/as participantes de um curso voltado à educação para a diversidade. Tese (Doutorado) - UFRGS, Porto Alegre, 2009.

EPSTEIN, D.; JOHNSON, R. Sexualidades e institución escolar. Madrid: Morata; La Coruña: Fundación Paideia, 2000.

ESPERANÇA, A. Homossexualidade: os significados e sentidos para docentes e discentes de cursos de Licenciatura da Universidade Federal do Amazonas. Dissertaçáo (Mestrado) - UFA, Manaus, 2009.

FAVA, C. Sexualidade como tema transversal nas escolas: da teoria à prática. Dissertação (Mestrado) - UFSC, Florianópolis, 2004.

FERRARI, A. Revisando o passado e construindo o presente: o movimento gay como espaço educativo. Revista Brasileira de Educação, Campinas, n. 25, p. 105-115, jan./ abr. 2004.

FRANÇA, L. Educação sexual: uma análise da concepção dos professores de duas escolas estaduais do ensino fundamental de Curitiba. Dissertação (Mestrado) - UTP, Tuiuti do Paraná, 2008. 
FREITAG, M. Gênero e sexualidade nas diretrizes curriculares para a educação brasileira. Dissertação (Mestrado) - URB, Blumenau, 2004.

FURLANI, J. Direitos humanos, direitos sexuais e pedagogia queer: o que essas abordagens têm a dizer à Educação Sexual? In: JUNQUEIRA, R. Diversidade sexual na Educação: problematizaçóes sobre a homofobia nas escolas (Org.). Brasília: MEC/Secad/Unesco, 2009. p. 293-323.

JARDIM, D. Como e quando começar a orientação sexual na escola: a opinião dos professores do município de Embu-SP. Dissertaçáo (Mestrado) - UFSP, São Paulo, 2009.

JUNQUEIRA, R. Diversidade sexual na Educação: problematizaçóes sobre a homofobia nas escolas (Org.). Brasília: MEC/Secad/Unesco, 2009.

GRÖSZ, D. Representaçôes de gênero no cotidiano de professoras e professores. Dissertaçẫo (Mestrado) - UFB, Distrito Federal, 2008.

KOERICH, M. História de uma presença-ausente: sexualidade e gênero em cursos de pedagogia. Dissertação (Mestrado) - UFSC, Santa Catarina, 2007.

LIRA, A. O tema transversal "orientaçấo sexual" nos PCN e atitude dos professores: convergentes ou divergentes? Dissertação (Mestrado) - UFRPe, Recife, 2009.

LOURO, G. O corpo educado: pedagogias da sexualidade. Belo Horizonte: Autêntica, 1999.

LOURO, G. Currículo, gênero e sexualidade - O "normal", o "diferente" e o "excêntrico". In: LOURO, G.; NECKEL, J. F.; GOELLNER, S. V. (Org.). Corpo, gênero e sexualidade: um debate contemporâneo na educação. Petrópolis: Vozes, 2003. p. 41-53.

LOURO, G. Um corpo estranho: ensaio sobre sexualidade e teoria queer. Belo Horizonte: Autêntica, 2006.

LOURO, G. Heteronormatividade e Homofobia. In: JUNQUEIRA, R. D. Diversidade sexual na Educação: problematizações sobre a homofobia nas escolas (Org.). Brasília: MEC/ Secad/Unesco, 2009. p. 85-93.

MADSEN, N. A construção da agenda de gênero no sistema Educacional Brasileiro (19962007). Dissertação (Mestrado) — UNB, Brasília, 2008.

MARCHI, M. Orientação sexual como tema transversal: um estudo exploratório sobre representaçôes de professoras. Dissertação (Mestrado) - UFR, Roraima, 2000.

MARSIGLIA, D. Silêncio e invisibilidade: a atitude discriminatória de professores diante da homossexualidade na escola. Dissertação (Mestrado) - UNJ, São Paulo, 2009.

MOEHLECKE, S. As políticas de diversidade na educação no Governo Lula. Cadernos de Pesquisa, v. 39, n. 137, p. 461-87, maio/ago. 2009.

MOSTAFA, M. Professores na encruzilhada entre o público e o privado: o curso Gênero e Diversidade na Escola. Dissertaçáo (Mestrado) - Uerj, Rio de Janeiro, 2009.

OLIVEIRA, A. O discurso pedagógico pela diversidade sexual e sua (re) articulação no campo escolar. Tese (Doutorado) - UFPe, Recife, 2009. 
PARRÉ, S. Aplicação dos Parâmetros Curriculares Nacionais na área de orientação sexual no ensino fundamental: um diagnóstico. Dissertação (Mestrado) - Unesp, Bauru, 2001.

QUARTIERO, E. A Diversidade Sexual na Escola: produçáo de subjetividade e politicas públicas, Dissertação (Mestrado) - UFRGS, Porto Alegre, 2009.

RAMOS, M.; ADÁO, J.; BARROS, G.(Coord.). Diversidade na educação: reflexóes e experiências. Brasília: SEMT, 2003.

REIS, E. Escola e sexualidades: diferentes concepçôes/muitos desafios. Dissertação (Mestrado) - UFF, Rio de Janeiro, 2009.

RIBEIRO, C. Saberes, poderes, verdades: imbricando rizomaticamente gêneros, sexualidades e E(e)ducaçăo. Revista Instrumento, Juiz de Fora, v. 12, n. 2, p.147-154, jul./dez. 2010.

RIBEIRO, J. F. Sexualidade na escola: um olhar sobre os Parâmetros Curriculares Nacionais. Dissertação (Mestrado) - UFJF, Juiz de Fora, 2009.

RIOS, R. Homofobia na perspectiva dos direitos humanos e no contexto dos estudos sobre preconceito e discriminação. In: JUNQUEIRA, R. Diversidade sexual na Educação: problematizaçôes sobre a homofobia nas escolas (Org.). Brasília: MEC/Secad/Unesco, 2009. p. 53-83.

ROSSI, A. Avanços e limites no combate à homofobia: uma análise do processo de implementação do Programa Brasil sem Homofobia. Dissertação (Mestrado) - UFRGS, Porto Alegre, 2010.

SANTOS, D. Documentos de subjetivação: um estudo sobre o currículo em um programa de formação de gênero. Dissertação (Mestrado) - Ufpa, Belém, 2009.

SANTOS, L. Corpo, gênero e sexualidade: educar meninas e meninos para além da homofobia. Dissertação (Mestrado) - UFSC, Florianópolis, 2008.

SCOTT, J. Gender and the Politics of History. New York: Columbia University Press, 1988.

SEFFNER, F. Equívocos e armadilhas na articulação entre diversidade sexual e políticas de inclusão escolar. In: JUNQUEIRA, R. Diversidade sexual na Educação: problematizaçóes sobre a homofobia nas escolas (Org.). Brasília: MEC/Secad/Unesco, 2009. p. 125-139.

SILVA, C. A igualdade ainda vai chegar: desafios para a construção da 'cultura do respeito' aos direitos de cidadania do segmento LGBTT em uma escola pública do município de São Paulo. Tese (Doutorado) - Feusp, São Paulo, 2010.

SILVA, S. A mulher professora e a sexualidade: representaçôes e práticas no espaço escolar. Dissertação (Mestrado) - UFM, São Luís, 2009.

TUCKMANTEL, M. A educação sexual: mas qual? Diretrizes para formação de professores em uma perspectiva emancipatória. Tese (Doutorado) - Unicamp, São Paulo, 2009.

VIANNA, C.; CARVALHO, M.; SCHILLING, F.; MOREIRA, M. Gênero, sexualidade e educação formal no Brasil: uma análise preliminar da produção acadêmica entre 1990 e 2006. Educação e Sociedade, v. 32, n. 115, p. 525-545, abr./jun. 2011. 
VIANNA, C.; UNBEHAUM, S. O gênero nas políticas públicas de educação no Brasil: 1988-2002. Cadernos de Pesquisa, São Paulo: Autores Associados, v. 34, n. 121, p. 77-104, jan./abr. 2004.

VIANNA, C.; UNBEHAUM, S. Gênero na educação básica: quem se importa? uma análise de documentos de políticas públicas no Brasil. Educação e Sociedade, Campinas, v. 28, n. 95, p. 407-428, maio/ago. 2006.

Recebido em 09 de setembro de 2010, modificado em 25 de outubro de 2011 e aprovado em 11 de janeiro de 2012. 
No v. 23, n.2(68), maio/ago. 2012, na página 142, a referência correta é: QUARTIERO,

E. A Diversidade Sexual na Escola: produção de subjetividade e políticas públicas, Dissertação (Mestrado) - UFRGS, Porto Alegre, 2009. 